\title{
Resveratrol prevents osteoporosis by upregulating FoxO1 transcriptional activity
}

\author{
YAN-LING FENG，XIAO-TONG JIANG，FANG-FANG MA，JIE HAN and XU-LEI TANG
}

The First Hospital of Lanzhou University, Lanzhou, Gansu 730000, P.R. China

Received November 24, 2016; Accepted October 12, 2017

DOI: $10.3892 / \mathrm{ijmm} .2017 .3208$

\begin{abstract}
Resveratrol (3,5,4-trihydroxystilbene, RES), a natural antioxidant, prevents bone loss by attenuating damage caused by oxidative stress. Our previous research revealed that the forkhead box $\mathrm{O} 1$ (FoxO1)/ $\beta$-catenin signaling pathway affected the proliferation and differentiation of osteoblasts through its regulation of redox balance, and RES regulated the expression of FoxO1 to control white adipose tissue and then ameliorate an overweight condition. Based on previous research, we hypothesized that RES regulates FoxO1 transcriptional activity through the phosphatidylinositol-3-kinase (PI3K)/AKT signaling pathway to achieve an antioxidative effect on osteoporosis and then we confirmed this hypothesis in the present study. An ovariectomized (OVX) rat model of osteoporosis and a $\mathrm{H}_{2} \mathrm{O}_{2}$-induced oxidative cell injury model in RAW 264.7 cells were established to explore the underlying molecular mechanisms of how RES confers an antioxidant effect and prevents bone loss. The obtained results demonstrated that RES strongly prevented bone loss induced by oxidative stress in vivo. More specifically, RES effectively decreased the receptor activator of nuclear factor- $\kappa \mathrm{B}$ ligand (RANKL) together with the tartrate-resistant acid phosphatase-5b (TRAP-5b) level, but elevated the osteoproprotegrin (OPG) level and attenuated bone microarchitecture damage. Notably, RES, due to its antioxidant effect, suppressed RANKL production and then inhibited osteoclastogenesis in the OVX rats. In vitro, RES improved the oxidative stress status of cells and thus inhibited the mRNA expression of osteoclast-specific enzymes. These data indicate that RES has a significant bone protective effect by antagonizing oxidative stress to suppress osteoclast activity, function and formation both in vivo and in vitro. Moreover, at the molecular level, we confirmed, for the first time, that RES upregulated FoxO1 transcriptional activity by inhibiting the PI3K/AKT signaling pathway, and hence promoted resistance to oxidative damage and restrained
\end{abstract}

Correspondence to: Dr Xu-Lei Tang, The First Hospital of Lanzhou University, 1 Donggong West Road, Lanzhou, Gansu 730000, P.R. China

E-mail: xulei_tang@126.com

Key words: resveratrol, resveratrol, osteoporosis, forkhead box $\mathrm{O} 1$ osteoclastogenesis. Inhibition of the PI3K/AKT signaling pathway may be induced by RANKL. FoxO1 is a major action target of RES to confer anti-osteoporosis function, and whose effect stems from its power to improve redox balance.

\section{Introduction}

Osteoporosis is a metabolic disease of bone, characterized by bone mass decrease, bone microarchitecture deterioration and increasing risk of fracture, since the bone resorption by osteoclasts surpasses the bone formation by osteoblasts. A variety of local and circulating hormones, cytokines and intermediary metabolites may affect the number and activity of both boneforming osteoblasts and bone resorption osteoclasts $(1,2)$. Currently, there is a growing body of study demonstrating that oxidative stress plays a crucial role in the pathophysiology of osteoporosis (1,3-7). Here, oxidative stress is caused when the production of reactive oxygen species (ROS) exceeds the antioxidant defense capacity (8). Abundant evidence has demonstrated that ROS can elevate the receptor activator of nuclear factor $-\kappa \mathrm{B}$ ligand (RANKL) expression in mouse osteoblasts and in human MG63 cells, and then stimulate the differentiation of osteoclasts from its precursor and therefore result in increased bone resorption (9-11). Accordingly, in the environment of the bone, the elevated level of ROS leads to increased bone resorption and impaired osteoblast function. That is, oxidative stress indeed takes part in the regulation of bone mass and is the chief culprit of osteoporosis (12).

In addition, ROS can trigger activation of specific physiologic signaling pathways. Cells protect themselves against the adverse effect of ROS by upregulating enzymatic scavengers or expression of DNA damage repair genes. This reaction involves dephosphorylation and subsequent activation of a small family of ubiquitous transcription factors known as Forkhead box O (FoxOs) (13-15). FoxOs, as important antioxidant defense factors, promote oxidative stress resistance in mammals $(16,17)$. Rached et al reported that, among the 4 FoxO proteins (FoxO1, FoxO3, FoxO4 and FoxO6), only FoxO1 is required for proliferation and redox balance in osteoblasts through cell-specific deletion and molecular analyses, and as a result FoxO1 controls bone formation (12). FoxO1 activation is normally restrained by the phosphatidylinositol-3-kinase (PI3K)/AKT signaling pathway, which prevents FoxO1 translocation into the nucleus, and it counteracts the generation of ROS by upregulating the 
expression of antioxidant enzymes [glutathione peroxidase (GSH-PX)] and superoxide dismutase (SOD) (18-20). In addition, the oxidative stress induced by homocysteine deranges insulin-sensitive FoxO1 and MAP kinase signaling cascades to decrease osteoproprotegrin (OPG) and increase RANKL synthesis in osteoblast cultures, leading to the stimulation of the osteoclast formation (21). Furthermore, Bartell et al elucidated that macrophage colony-stimulating factor (M-CSF) and RANKL promote the accumulation of $\mathrm{H}_{2} \mathrm{O}_{2}$ in osteoclasts along with their progenitors via an AKT-mediated repression of FoxO transcription which lowers catalase protein level.

Resveratrol (3,5,4-trihydroxystilbene, RES), a natural polyphenolic component extracted from red grapes, peanuts and other plants, is known to exert many beneficial pharmacological effects such as antitumor, scavenging free radicals, anti-inflammation, cardioprotection and vasoprotection activities (22-24). Clinical and experimental studies have shown that RES prevents bone loss by attenuating the damage caused by oxidative stress. RES can induce the production of major cellular antioxidant enzymes, such as GSH-PX, heme oxygenase and SOD, resulting in marked attenuation of oxidative stress $(25,26)$. Significantly, RES was also shown to inhibit mitochondrial production of ROS in the vasculature (27). Furthermore, a previous study confirmed that RES intake relieved alveolar bone resorption and improved systemic oxidative stress in a rat periodontitis model (28). Bhattarai et al also demonstrated that RES treatment exhibited multiple beneficial effects for suppressing alveolar bone loss and these effects were the result of its antioxidative, anti-inflammatory, bone formation stimulating, and anti-osteoclastogenic activity (29). It is believed that the bone protective effect of RES is primarily due to its antioxidant activity. More importantly, RES exhibited no toxic effects, and therefore RES can be safely used for the treatment and/or prevention of osteoporosis, even if used for a long time (30). However, the explicit molecular mechanisms of how RES, as a natural antioxidant, plays a major role in preventing bone loss, have not yet been well understood.

Additionally, our previous research revealed that the effects of the FoxO1/ $\beta$-catenin signaling pathway on the proliferation and differentiation of osteoblasts are achieved through its regulation of redox balance via the upregulation of antioxidant enzyme levels as well as the expression of DNA damage repair-related gene Gadd45, while inhibiting the expression of apoptosis-related gene Bim along with the osteoblast inhibition gene peroxisome proliferator-activated receptor- $\gamma$ (PPAR- $\gamma)$. On the other hand, RES regulates the expression of FoxO1 by inhibiting the PI3K/AKT signaling pathway to control white adipose tissue and then ameliorate an overweight condition induced by a high fat diet. Based on the above studies, we speculate that RES regulates FoxO1 transcriptional activity via the PI3K/AKT signaling pathway to protect against oxidative damage in osteoporosis. In order to further confirm this speculation, in the present study, we established an ovariectomized (OVX) rat model of osteoporosis in vivo and an osteoclast oxidative stress model induced by $\mathrm{RANKL}$ and $\mathrm{H}_{2} \mathrm{O}_{2}$ in RAW 264.7 cells in vitro to explore the underlying molecular mechanisms of how RES exhibits an antioxidant effect and prevents bone loss. Implementation of this project revealed the effect of RES against oxidative stress damage together with its molecular mechanisms, and also provides a new scientific basis for the clinical application of RES in the prevention and/or treatment of osteoporosis.

\section{Materials and methods}

Ovariectomy and administration of RES. Thirty female Sprague-Dawley (SD) rats, aged 3 months, body weight $220 \pm 19.27 \mathrm{~g}$, were purchased from Gansu University of Chinese Medicine and were equally divided into three groups randomly. Ten rats were administered sham operation (control rats; Sham group) and 20 rats underwent bilateral OVX under $10 \%$ chloral hydrate anesthesia (OVX group). One week postoperative, all rats were administered the medicine by subcutaneous injection: the Sham group and OVX group received equal amount of sesame oil (vehicle; Sigma-Aldrich, St. Louis, MO, USA); the third group (OVX+RES group) received RES solution (40 $\mathrm{mg} / \mathrm{kg}$ body weight, once daily; Sigma-Aldrich). After treatment for 10 weeks, the rats were sacrificed, and the blood along with the bone were collected for further analyses. All experiments performed involving SD rats were approved by the Animal Experimental Ethical Inspection of Gansu University of TCM (permission code 2015-060).

Bone $\mu$-CT scanning. We dissected the femurs, cleaned the soft tissues, fixed them in $10 \%$ neutral formalin for $48 \mathrm{~h}$, and then immersed them into $70 \%$ ethanol. Bone microarchitecture in the middle and distal femur was scanned by using micro-computed tomography ( $\mu$-CT; VivaCT 40; Scanco, Brüttisellen, Switzerland) with $15 \mu \mathrm{m}$ resolution, tube voltage of $70 \mathrm{kV}$ and tube current of $114 \mu \mathrm{A}$. The reconstruction and $3 \mathrm{D}$ quantitative analyses were performed using software provided by a desktop $\mu$-CT system (VivaCT 40; Scanco). In the femur, cortical bone volume (Ct.Vo) and cortical thickness (Ct.Th) were analyzed with the help of the reference point at the mid-diaphysis, with whole cortical bone, where the region of interest (ROI) was $1.0 \mathrm{~mm}$. Trabecular bone region reference point was at the growth plate joining, offset $2.0 \mathrm{~mm}$, ROI $2.0 \mathrm{~mm}$. The following 3D parameters in the defined ROI were analyzed, including the relative bone volume over total volume (BV/TV, \%), trabecular number (Tb.N), trabecular thickness (Tb.Th), trabecular separation (Tb.Sp), connectivity density (Conn.D), structure model index (SMI) and bone mineral density (BMD).

Bone histomorphometric analysis. The right isolated tibias maintained in $70 \%$ alcohol were used for the bone shape analysis. The processes of alcohol dehydration, xylene transparency undecalcified plastic embedding, sectioning (thickness of $30 \mu \mathrm{m}$ ) followed by Van Gieson staining were included. Bone morphological measurement indices were analyzed using IPP 6.0 analysis software.

Enzyme-linked immunosorbent assay (ELISA) measurement. Rat OPG, RANKL and tartrate-resistant acid phosphatase5b (TRAP-5b) ELISA kits as well as an ROS ELISA kit were purchased from Myhalic Biotechnology Co., Ltd. (http://www.myhalic.com/; Wuhan, China). MDA, SOD and GSH-PX were measured by employing specific kits (Jiancheng, Nanjing, China) following the manufacturer's instructions. 
Table I. RT-PCR primers employed for amplification of specific mRNAs.

\begin{tabular}{lll}
\hline Gene & \multicolumn{1}{c}{ Forward (5'-3') } & \multicolumn{1}{c}{ Reverse (5'-3') } \\
\hline Actb & CATCCGTAAAGACCTCTATGCCAAC & ATGGAGCCACCGATCCACA \\
MMP-9 & CCATGCACTGGGCTTAGATCA & GGCCTTGGGTCAGGCTTAGA \\
TRAP & GTGCTGGCTGGAAACCATGA & GTCCAGCATAAAGATGGCCACA \\
Cathepsin K & CACCCAGTGGGAGCTATGGAA & GCCTCCAGGTTATGGGCAGA \\
\hline
\end{tabular}

TRAP, tartrate-resistant acid phosphatase; MMP-9, matrix metalloproteinase-9.

Cell culture. The mouse macrophage cell line RAW 264.7, purchased from the American Type Culture Collection (ATCC, TIB-71 ${ }^{\mathrm{TM}}$; Manassas, VA, USA), was cultured in highglucose Dulbecco's modified Eagle's medium (DMEM; Gibco, Grand Island, NY, USA) containing $10 \%$ fetal bovine serum (FBS; TAN, South America) in a $25 \mathrm{~cm}^{2}$ culture flask at $37^{\circ} \mathrm{C}$ in a $5 \% \mathrm{CO}_{2}$ incubator. Culture media were changed every other day. Cells were incubated in an osteoclastic induction medium supplemented with $100 \mathrm{ng} / \mathrm{ml}$ RANKL (315-11; PeproTech, Rocky Hill, NJ, USA) for 7 days. This cell line has been shown to express receptor activator of NF- $\mathrm{kB}$ (RANK) and differentiate into TRAP-positive, functional osteoclasts when co-cultured with soluble RANKL $(31,32)$. The RAW 264.7 cells were cultured to $80 \%$ confluence, and the medium was replaced according to the specific group. The cultured cells were randomly divided into four groups: the RANKL control group, $10^{-4} \mathrm{M} \mathrm{H}_{2} \mathrm{O}_{2}$ group, $10^{-5} \mathrm{M}$ RES group, and $10^{-4} \mathrm{M}$ $\mathrm{H}_{2} \mathrm{O}_{2}$ plus $10^{-5} \mathrm{M}$ RES group. We would like to stress that in the latter three groups, the cells were also incubated in an osteoclastic induction medium supplemented with $100 \mathrm{ng} / \mathrm{ml}$ RANKL. $\mathrm{H}_{2} \mathrm{O}_{2}$ was added $1 \mathrm{~h}$ prior to treatment with RES. All of the experiments were repeated 3 or 5 times.

Cytotoxicity assay. The cytotoxic effects of RES or $\mathrm{H}_{2} \mathrm{O}_{2}$ were detected using Cell Counting kit-8 (CCK-8; Jiancheng), according to the manufacturer's instructions. Briefly, 8,000 cells were seeded per well on a $96-$ well plate. The cells were treated with $10^{-5} \mathrm{M}$ RES or $10^{-4} \mathrm{M} \mathrm{H}_{2} \mathrm{O}_{2}$ and cultured for 24,48 and $72 \mathrm{~h}$, respectively, to measure the toxicity at $450 \mathrm{~nm}$ using a microplate reader.

TRAP staining. After induction of culture for 7 days, TRAP staining was performed to evaluate $\mathrm{TRAP}(+)$-multinucleated osteoclast formation. RAW 264.7 cells were cultured on a 24-well plate at a density of $2 \times 10^{4}$ cells/well and allowed to adhere overnight. DMEM was then replaced, and the cells were treated with new DMEM containing $100 \mathrm{ng} / \mathrm{ml}$ RANKL. After induced culture for 7 days, the cells were stained for TRAP expression using an Acid Phosphatase, Leukocyte (TRAP) kit (387-A; Sigma-Aldrich) following the manufacturer's instructions.

Assessment of the culture supernatant MDA, SOD and $G S H-P X$. We harvested the culture supernatant after the RAW 264.7 cells were cultured as mentioned in the different groups in the induction medium for $24 \mathrm{~h}$ on 96 -well plates at a density of 8,000 cells/well, and we assessed the MDA,
SOD and GSH-PX by employing the relevant kits (Jiancheng) according to the manufacturer's instructions.

IntracellularROSformation. The generation ofROS was probed with the ROS fluorescent probe-dihydroethidium (DHE). Cells were plated on 6-well plates at $6 \times 10^{4}$ cells/well, and were induced-cultured in terms of the above groups for $24 \mathrm{~h}$. After this treatment, the cells were washed with PBS and then incubated with $20 \mu \mathrm{M}$ DHE for $30 \mathrm{~min}$ at $37^{\circ} \mathrm{C}$. DHE is oxidized by ROS when it diffuses into the cells, and then the intracellular oxidized DHE was measured via flow cytometry.

Real-time PCR. Cells were plated in a $25 \mathrm{~cm}^{2}$ flask at $2 \times 10^{5}$ cells/flask, and induced-cultured in regards to the above groups for 7 days. Total RNA was extracted from the cultured cells applying RNAiso ${ }^{\mathrm{TM}}$ Plus (cat. no. 9108; Takara, Tokyo, Japan). The RNA concentration was determined spectrophotometrically, and only pure RNA (A260:A280 ratio in 1.8-2.1) was used for further analysis. Total RNA (5 $\mu \mathrm{l})(500 \mathrm{ng})$ from each sample was reverse-transcribed using PrimeScript ${ }^{\mathrm{TM}}$ RT Master Mix (perfect real-time) (code: RR036A; Takara). Complementary DNA was mixed with SYBR Premix Ex Taq ${ }^{\mathrm{TM}}$ II (Tli RNaseH Plus) (code: RR820A; Takara) and then was subjected to PCR amplification using the LightCycler/LightCycler 480 system real-time PCR. Denaturation was carried out at $95^{\circ} \mathrm{C}$ for $30 \mathrm{sec}$ (ramp rate $4.4^{\circ} \mathrm{C} / \mathrm{sec}$ ) 1 cycle; PCR (quantification) at $95^{\circ} \mathrm{C}$ for $5 \mathrm{sec}$ (ramp rate $4.4^{\circ} \mathrm{C} / \mathrm{sec}$ ) and $60^{\circ} \mathrm{C}$ for $30 \mathrm{sec}\left(\right.$ ramp rate $2.2^{\circ} \mathrm{C} / \mathrm{sec}$ ) 40 cycles; melting (melting curves) was performed at $95^{\circ} \mathrm{C}$ for $5 \mathrm{sec}$ (ramp rate $4.4^{\circ} \mathrm{C} / \mathrm{sec}$ ) followed by $60^{\circ} \mathrm{C}$ for $60 \mathrm{sec}$ (ramp rate $2.2 / \mathrm{sec}$ ) and $95^{\circ} \mathrm{C}$ (ramp rate $0.11^{\circ} \mathrm{C} / \mathrm{sec}$, acquisition mode: continuous, acquisitions: 5 per) 1 cycle; and cooling was carried out at $50^{\circ} \mathrm{C}$ for $30 \mathrm{sec}$ [ramp rate $2.2^{\circ} \mathrm{C} / \mathrm{sec}$ ) 1 cycle]. The primers used for real-time PCR are listed in Table I.

Western blot analysis. The cells were plated in a $25 \mathrm{~cm}^{2}$ flask with $2 \times 10^{5}$ cells/flask, and induced-culture was carried out in terms of the above groups for 7 days. Cells were lysed using a lysis buffer containing $50 \mathrm{mM}$ Tris (pH 7.4), $150 \mathrm{mM} \mathrm{NaCl}$, $1 \%$ Triton X-100, $1 \%$ sodium dexycholate, 0:1\% SDS, sodium orthovanadate, sodium fluoride, EDTA, and leupeptin inhibitor (code P0013B; Beyotime, Shanghai, China). The lysates (20-30 $\mu \mathrm{g}$ ) were separated using 10\% sodium dodecyl sulfatepolyacrylamide gel electrophoresis (SDS-PAGE) and transferred to nitrocellulose blotting membranes. After blocking with 5\% skim milk (detection of phosphorylated proteins with BSA) for $1 \mathrm{~h}$ at room temperature, the membranes were incubated with 
Table II. Trabecular microstructural and cortical geometric properties of the right femurs evaluated ex vivo using $\mu$-CT.

\begin{tabular}{lcrr}
\hline Parameters & Sham & OVX & OVX+RES \\
\hline BV/TV $(\%)$ & $47.48 \pm 6.00$ & $20.88 \pm 7.53^{\mathrm{b}}$ & $36.14 \pm 8.62^{\mathrm{a}, \mathrm{c}}$ \\
Tb.N $(1 / \mathrm{mm})$ & $4.90 \pm 0.61$ & $2.94 \pm 0.79^{\mathrm{b}}$ & $4.79 \pm 0.26^{\mathrm{d}}$ \\
Tb.Th $(\mu \mathrm{m})$ & $81.43 \pm 16.64$ & $51.80 \pm 3.74^{\mathrm{a}}$ & $78.67 \pm 14.76^{\mathrm{c}}$ \\
Tb.Sp $(\mathrm{mm})$ & $0.13 \pm 0.03$ & $0.24 \pm 0.04^{\mathrm{b}}$ & $0.13 \pm 0.02^{\mathrm{d}}$ \\
Conn.D $\left(1 / \mathrm{mm}^{3}\right)$ & $155.59 \pm 22.56$ & $108.78 \pm 18.59^{\mathrm{b}}$ & $144.86 \pm 28.12^{\mathrm{c}}$ \\
SMI & $0.42 \pm 0.13$ & $1.87 \pm 0.27^{\mathrm{b}}$ & $1.23 \pm 0.20^{\mathrm{b}, \mathrm{d}}$ \\
BMD $\left(\mathrm{mg} \mathrm{HA}^{\mathrm{c}} \mathrm{ccm}\right)$ & $732.42 \pm 15.68$ & $693.79 \pm 11.46^{\mathrm{a}}$ & $729.66 \pm 4.81^{\mathrm{c}}$ \\
Ct.Vo $\left(\mathrm{mm}^{3}\right)$ & $4.86 \pm 0.64$ & $5.18 \pm 0.50$ & $5.52 \pm 0.87$ \\
Ct.Th $\left(\mathrm{mm}^{3}\right.$ & $2.82 \pm 0.90$ & $2.72 \pm 0.27$ & $2.86 \pm 1.17$ \\
\hline
\end{tabular}

Results are presented as the mean $\pm \mathrm{SD}$. ${ }^{\mathrm{a}} \mathrm{P}<0.05$ and ${ }^{\mathrm{b}} \mathrm{P}<0.01 \mathrm{vs}$. Sham group; ${ }^{\mathrm{c}} \mathrm{P}<0.05$ and ${ }^{\mathrm{d}} \mathrm{P}<0.01 \mathrm{vs}$. OVX group (n=5-7/group). OVX, ovariectomized; BMD, bone mineral density; SMI, structure model index; Tb.N, trabecular number; Tb.Th, trabecular thickness; Tb.Sp, trabecular separation; Conn.D, connectivity density; Ct.Vo, cortical bone volume; Ct.Th, cortical thickness.

anti- $\beta$-actin (1:5,000; ab6276), anti-AKT (1:500; ab28422), antip-AKT (1:500; ab8932), anti-FoxO1 (1:1,000; ab52857), and anti-p-FoxO1 (1:500; ab131339) (all from Abcam, Cambridge, UK) antibodies overnight at $4^{\circ} \mathrm{C}$, and then were incubated with the secondary antibody (1:1,000; Santa Cruz Biotechnology, Inc., Santa Cruz, CA, USA) for $1 \mathrm{~h}$ at $37^{\circ} \mathrm{C}$.

Analysis of apoptosis. Cells were plated on 6-well plates at $6 \times 10^{4}$ cells/well, and cultured in terms of the above groups for 3 days. After this treatment, cells were washed with phosphatebuffered saline (PBS) and then apoptosis was assessed using the Annexin V/PI double staining assay via flow cytometry.

Statistical analysis. Data are expressed as mean \pm standard deviation (SD). The values were analyzed by employing a one-way ANOVA of variance followed by a LSD test for multiple comparisons. The statistical significance was defined as $\mathrm{P}<0.05$. Error bars in all figures represent SD.

\section{Results}

RES prevents the deterioration of trabecular bone microarchitecture induced by $O V X$. One week postoperative, we administered RES ( $40 \mathrm{mg} / \mathrm{kg}$ body weight, once daily) to OVX rats for 10 weeks to examine its protective effects against bone loss. The animals were all sacrificed 11 weeks after the operation. When compared with the Sham group rats, OVX significantly induced deterioration of the trabecular bone microarchitecture, and reduction in BV/TV, Tb.N, Tb.Th, Conn.D and BMD $(\mathrm{P}<0.05$ and $\mathrm{P}<0.01)$ (Table II). In contrast, other microstructural parameters such as Tb.Sp and SMI were sharply increased in response to OVX $(\mathrm{P}<0.01)$. However, treatment of OVX rats with RES at $40 \mathrm{mg} / \mathrm{kg}$ body weight markedly reversed changes in these parameters induced by OVX. In $\mu$-CT images of the distal femur, these changes in trabecular bone parameters were readily observed (Fig. 1A). Ct.Vo and Ct.Th as determined by $\mu$-CT were also analyzed (Table II). OVX did not affect the cortical bone volume and thickness of the femur mid-diaphysis (P>0.05). Simultaneously, bone histomorphology of the right tibias detected using Van Gieson staining were carried out and also exhibited similar results (Fig. 1B). The trabecular number was decreased and spaces between trabecules were broader in the OVX group compared with the Sham group. Nevertheless, treatment with RES significantly inhibited the OVX-induced deleterious effects, as demonstrated in the OVX+RES group via an increase in the trabecular number and a decrease in the trabecular space. The analysis of the properties of trabecular and cortical bone in the middle and distal femurs indicated that OVX induces damage of the trabecular bone micro-architecture in rats, yet RES was able to attenuate the damage effects.

RES suppresses osteoclast activity and formation. In order to determine the possible regulatory effects of RES on osteoclast activity and formation, we examined the production of TRAP-5b, OPG and RANKL in the serum of rats. TRAP-5b is released by osteoclasts, reflecting osteoclast activity and the bone resorption status. Upon comparison with the Sham group, the TRAP-5b content in the serum was increased following OVX. Yet, as shown in Fig. 2A, RES markedly reversed the change $(\mathrm{P}<0.01)$. OPG and RANKL are primarily released from osteoblasts. Osteoblast-derived RANKL binds to RANK on osteoclasts, resulting in osteoclast activation. OPG, osteoclastogenesis inhibitory factor, has also been demonstrated to compete with RANKL for binding to RANK, leading to suppression of osteoclast formation. Thus, osteoclast formation is reflected by the ratio of OPG/RANKL. Compared with the Sham group, as shown in Fig. 2B, the level of OPG was reduced, while RANKL was enhanced, and OPG/RANKL was significantly decreased in response to OVX $(\mathrm{P}<0.01)$. However, RES intervention recovered at least part of the changes $(\mathrm{P}<0.01)$ in the parameters induced by OVX. Our results revealed that, under OVX, osteoclast activity and formation were enhanced, while RES greatly weakened the OVX effects.

RES improves the antioxidant power in the rats. To further confirm the fact that bone protective effects of the RES are primarily caused by antagonizing the OVX-induced oxidative stress damage, the levels of MDA, ROS, SOD and GSHPX in the serum of rats were determined. Analysis of the oxidative 

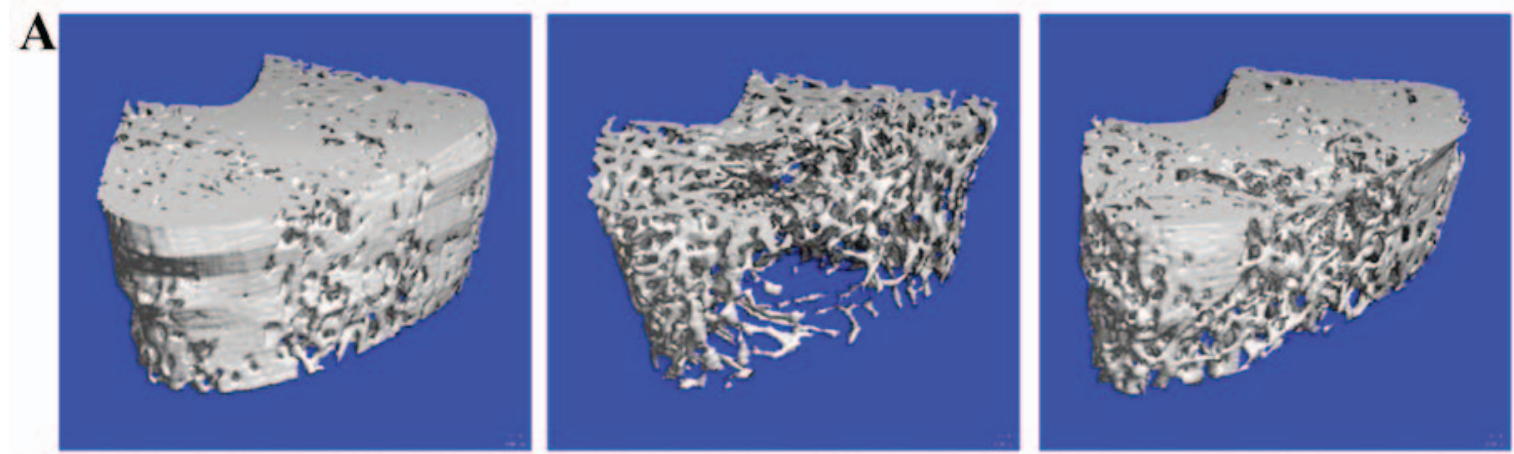

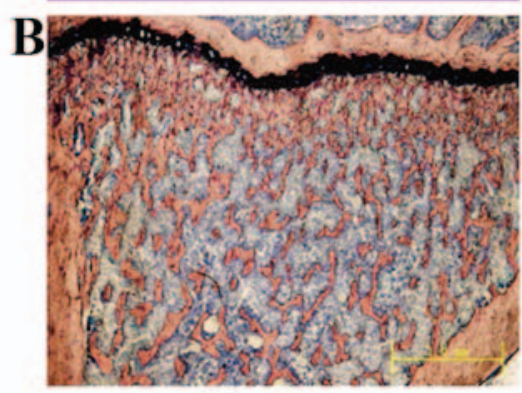

Sham

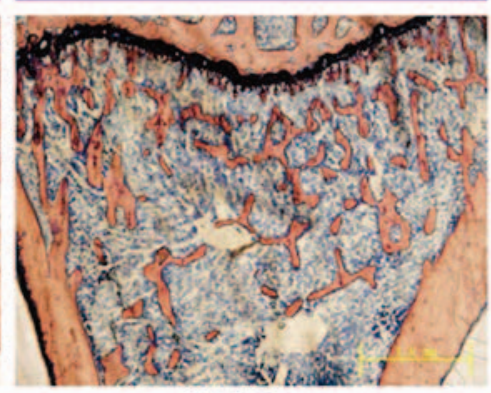

OVX

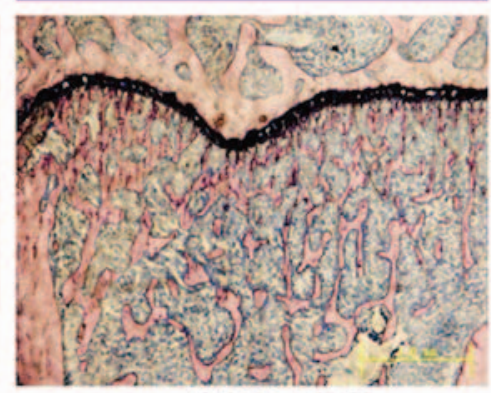

OVX+RES

Figure 1. Resveratrol (RES) prevents bone microarchitecture damage induced in ovariectomized (OVX) rats. (A) The right femurs of rats were scanned using $\mu$-CT in the Sham group, OVX group and OVX+RES group. (B) Bone histomorphology of the right tibias was assessed using Van Gieson staining in the Sham group, OVX group and OVX+RES group (10 x 4).
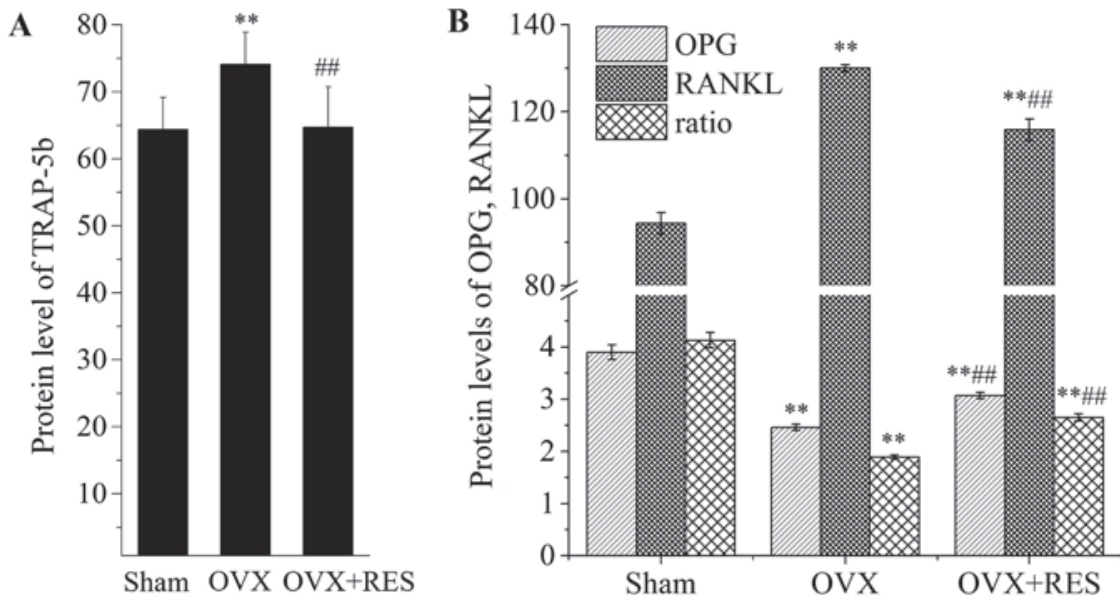

Figure 2. Osteoclast activity and formation are restrained by resveratrol (RES) in vivo. The protein levels of tartrate-resistant acid phosphatase-5b (TRAP-5b), osteoproprotegrin (OPG) and receptor activator of nuclear factor- $\kappa \mathrm{B}$ ligand (RANKL) in the serum of rats were examined by applying enzyme-linked immunosorbent assay (ELISA) kits. (A) RES lowered the TRAP-5b level in the serum of rats in the ovariectomized (OVX)+RES group. (B) RES intervention elevated the OPG/RANKL ratio (namely, OPG enhancement vs. RANKL decrease). Values are expressed as mean \pm SD. ${ }^{* *} \mathrm{P}<0.01 \mathrm{compared}$ with the Sham group; ${ }^{\# \#} \mathrm{P}<0.01$ compared with the OVX group ( $\mathrm{n}=5-7 /$ group).

stress status of the experimental rats indicated that the Sham group also generated traces of MDA and ROS. When rats underwent the OVX operation, the MDA and ROS concentrations were increased, while the contents of SOD and GSH-PX were reduced, as compared with the Sham group. Upon treatment with RES to the OVX rats, changes were also observed when compared to the OVX group; that is, MDA and ROS levels were highly decreased while the antioxidant enzymes such as SOD and GSH-PX were markedly elevated $(\mathrm{P}<0.05$ and $\mathrm{P}<0.01$ ) (Fig. 3). On the whole, these findings indicated that OVX induced oxidative stress, resulting in a lowered OPG level but enhanced RANKL and TRAP-5b levels, and an increase in osteoclast formation together with activity, and eventually bone microarchitecture damage. Notably, RES enhanced the OPG content, lowered the RANKL and TRAP-5b levels, and finally reduced bone resorption by improving the oxidative stress status. Subsequently to explore the hidden molecular mechanisms of the bone protective effects of RES, we stimulated the RAW 264.7 cells with RANKL to induce osteoclasts in vitro. Before detecting the effects of $\mathrm{H}_{2} \mathrm{O}_{2}$ and RES on osteoclast activity along with function, the cell viability (Fig. 4) was determined. The potential cytotoxicity of these agents was tested since their toxicity would influence the cell survival and consequently lower the cell number. Either 

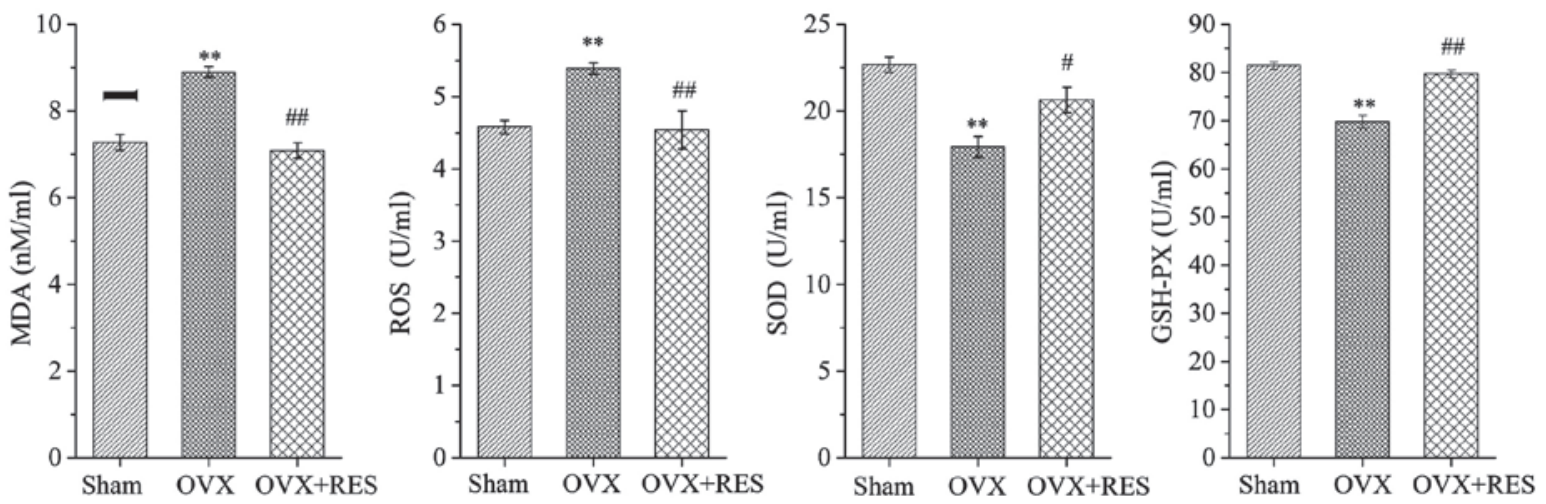

Figure 3. The ovariectomized (OVX)-induced oxidative stress damage is antagonized by resveratrol (RES) in vivo. The levels of MDA, reactive oxygen species (ROS), SOD and glutathione peroxidase (GSH-PX) in the serum of rats were determined. Following treatment of the OVX rats with RES, MDA and ROS levels were highly decreased and the antioxidant enzymes such as SOD and GSH-PX were markedly elevated. Values are expressed as mean \pm SD. ${ }^{*} \mathrm{P}<0.05$ and ${ }^{* *} \mathrm{P}<0.01$ compared to the Sham group; ${ }^{\text {\# }} \mathrm{P}<0.05$ and ${ }^{\# \#} \mathrm{P}<0.01$ compared to the OVX group (n=5-7/group).

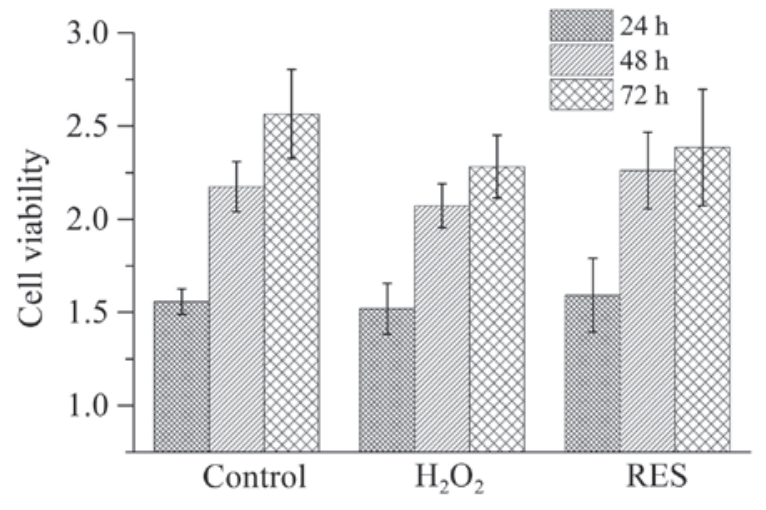

Figure 4. Cell viability as determined with Cell Counting kit-8 (CCK-8) assay. Results are expressed as OD values. Each bar represents the mean $\pm \mathrm{SD}$ of five independent experiments. Resveratrol (RES) at $10^{-5} \mathrm{M}$ increased the RAW 264.7 cell viability and $10^{-4} \mathrm{M} \mathrm{H}_{2} \mathrm{O}_{2}$ decreased the cell viability, but statistical differences were not achieved compared with the control group $(\mathrm{P}>0.05)$.

$10^{-4} \mathrm{M} \mathrm{H}_{2} \mathrm{O}_{2}$ or $10^{-5} \mathrm{M}$ RES did not have a cytotoxic effect on RAW 264.7 cells ( $\mathrm{P}>0.05)$.

RES reduces the expression of osteoclast-related marker enzymes. In order to evaluate the osteoclast activity in vitro, the expression of osteoclast marker enzymes was assessed by employing RT-PCR, including matrix metalloproteinase-9 (MMP-9), TRAP, and cathepsin K. Expressed specifically by osteoclasts, these three enzymes are important indices which reflect osteoclast activity as well as bone resorption function. As shown in Fig. 5, compared with the control group, the mRNA expression levels of MMP-9, TRAP and cathepsin $\mathrm{K}$ were increased $(\mathrm{P}<0.01)$ in the presence of $10^{-4} \mathrm{M} \mathrm{H}_{2} \mathrm{O}_{2}$, indicating that osteoclast activity along with bone resorption function was facilitated by $\mathrm{H}_{2} \mathrm{O}_{2}$. In contrast, following treatment of the cells with RES at $10^{-5} \mathrm{M}$, the expression levels of the osteoclast marker enzymes were reduced compared with the $\mathrm{H}_{2} \mathrm{O}_{2}$ group $(\mathrm{P}<0.01)$, indicating that RES inhibited osteoclast activity and bone resorption capacity.

RES abrogates oxidative stress in cells. To elucidate whether the inhibitory effects of RES on osteoclast activity and bone

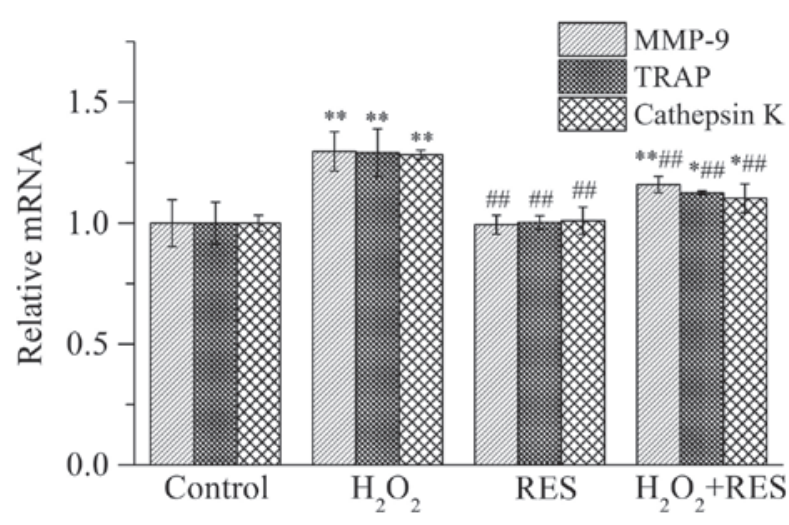

Figure 5. Expression of osteoclast marker enzymes was reduced by resveratrol (RES). To evaluate osteoclast activity, the mRNA expression of osteoclast marker enzymes (MMP-9, TRAP and cathepsin K) was assessed using RT-PCR. In the presence of RES, the effects of the stimulation of mRNA expression of osteoclast marker enzymes by $\mathrm{H}_{2} \mathrm{O}_{2}$ were greatly abolished. Results are presented as the mean $\pm \mathrm{SD}$. ${ }^{*} \mathrm{P}<0.05$ and ${ }^{* *} \mathrm{P}<0.01$ vs. the control group; ${ }^{\#} \mathrm{P}<0.05,{ }^{\# \#} \mathrm{P}<0.01$ vs. the $\mathrm{H}_{2} \mathrm{O}_{2}$ group.

resorption power are linked to its antioxidant properties, the MDA, ROS, SOD and GSH-PX levels were detected. As shown in Fig. 6, when RAW 264.7 cells were exposed to $10^{-4} \mathrm{M} \mathrm{H}_{2} \mathrm{O}_{2}$, the production of MDA and ROS was strongly enhanced, while the SOD and GSH-PX levels were decreased $(\mathrm{P}<0.01)$. The above results demonstrated that $\mathrm{H}_{2} \mathrm{O}_{2}$ stimulated oxidant generation and led to oxidative stress in RAW 264.7 cells. However, when the cells were treated with RES at a concentration of $10^{-5} \mathrm{M}$, MDA and ROS production was inhibited to some degree, while the SOD and GSH-PX levels were higher compared with the $\mathrm{H}_{2} \mathrm{O}_{2}$ group $(\mathrm{P}<0.05$ and $\mathrm{P}<0.01)$. The study revealed that RES improves the oxidative stress status of the cells, and the suppressive effects of RES on the expression of osteoclast marker enzymes are linked to its antioxidant activity.

RES regulates FoxO1 transcriptional activity by inhibiting the PI3K/AKT signaling pathway. The PI3K/AKT/FoxO1 signaling pathway plays a crucial role in osteoclastogenesis. Furthermore, to confirm the RES-attenuated oxidative stress damage and RES-suppressed osteoclastogenesis by inhibiting the PI3K/AKT signaling pathway, we evaluated the effects of 

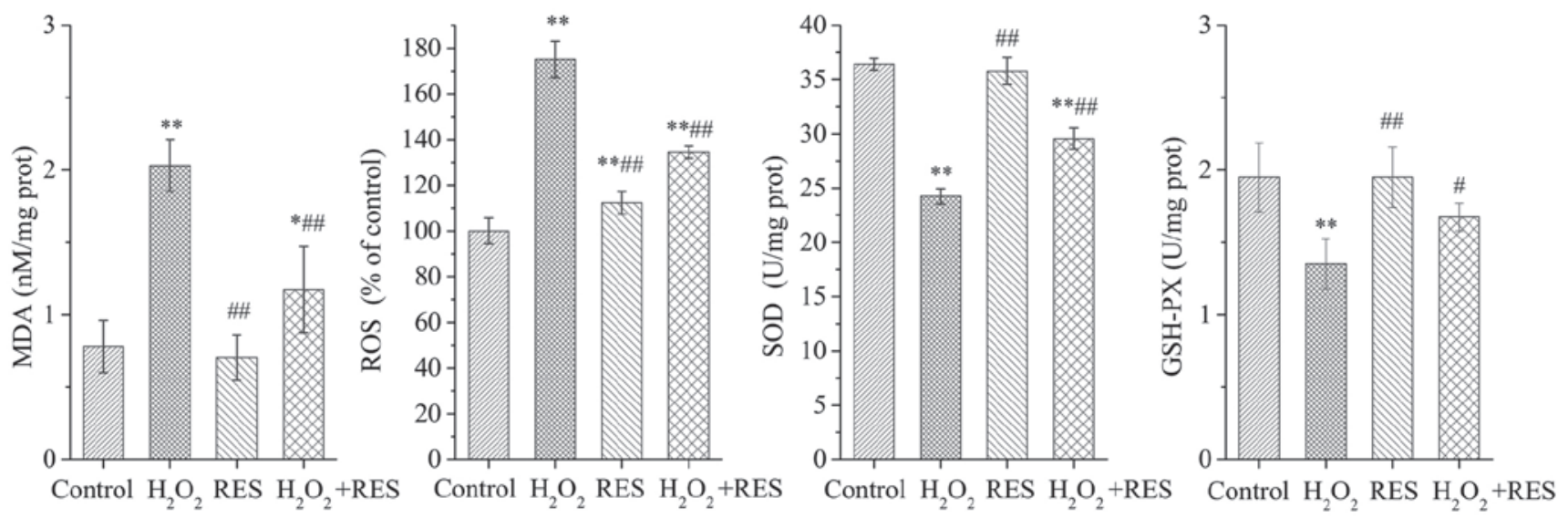

Figure 6. The oxidative stress status of the cells is improved by resveratrol (RES). RES suppressed the $\mathrm{H}_{2} \mathrm{O}_{2}$-induced elevation of MDA and reactive oxygen species (ROS) levels, yet improved the $\mathrm{H}_{2} \mathrm{O}_{2}$-induced decrease in antioxidant enzyme [SOD, glutathione peroxidase (GSH-PX)] levels. Results are presented as the mean $\pm \mathrm{SD}$. ${ }^{*} \mathrm{P}<0: 05$ and ${ }^{* *} \mathrm{P}<0: 01$ vs. the control group; ${ }^{*} \mathrm{P}<0: 05$ and ${ }^{\# \#} \mathrm{P}<0: 01$ vs. the $\mathrm{H}_{2} \mathrm{O}_{2}$ group.

A

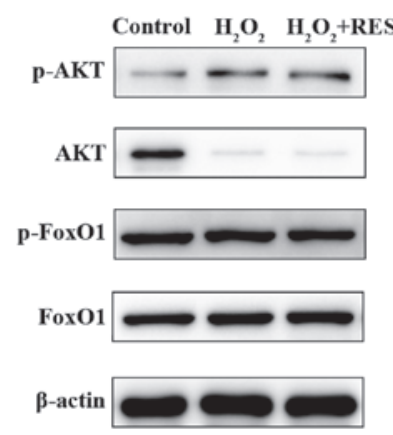

B

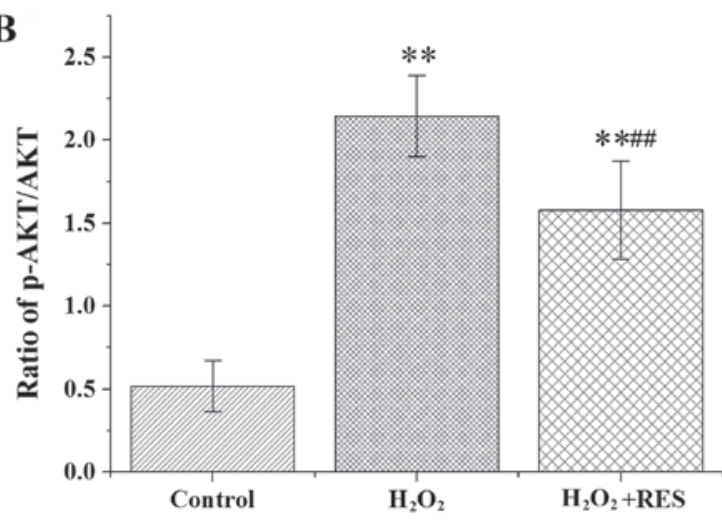

Figure 7. Forkhead box O1 (FoxO1) protein level is elevated by resveratrol (RES). (A) The protein levels of p-AKT, AKT, p-FoxO1 and FoxO1 were determined by western blot analysis. (B) RES lowered the ratio of p-AKT/AKT in osteoclasts from the $\mathrm{H}_{2} \mathrm{O}_{2}+\mathrm{RES}$ group in comparison with this ratio in osteoclasts from the $\mathrm{H}_{2} \mathrm{O}_{2}$ group. Results are presented as the mean \pm SD. ${ }^{* *} \mathrm{P}<0: 01$ vs. the control group; ${ }^{\# \#} \mathrm{P}<0: 01$ vs. the $\mathrm{H}_{2} \mathrm{O}_{2}$ group.

RES on the PI3K/AKT/FoxO1 signaling pathway following stimulation with $100 \mathrm{ng} / \mathrm{ml}$ RANKL in RAW 264.7 cells. AKT, phosphorylated AKT (p-AKT), FoxO1 and p-FoxO1 were examined by western blot analysis. Compared with the control group, $\mathrm{H}_{2} \mathrm{O}_{2}$ elevated the ratio of $\mathrm{p}-\mathrm{AKT} / \mathrm{AKT}$ and the protein content of p-FoxO1, yet the FoxO1 protein level was reduced $(\mathrm{P}<0.05$ and $\mathrm{P}<0.01)$ (Fig. 7). According to these results, FoxO1 transcriptional activity was suppressed by $\mathrm{H}_{2} \mathrm{O}_{2}$. Following treatment with RES, the above effects of $\mathrm{H}_{2} \mathrm{O}_{2}$ were abolished, at least in part $(\mathrm{P}<0.05$ and $\mathrm{P}<0.01)$. These data indicate the RES was able to upregulate FoxO1 transcriptional activity by inhibiting the PI3K/AKT signaling pathway. In brief, our results revealed that RES upregulated FoxO1 transcriptional activity to achieve attenuation of oxidative stress damage and inhibition of osteoclastogenesis.

$R E S$ regulates the apoptosis of RAW 264.7 cells. The inhibition of the PI3K/AKT signaling parthway leads to dephosphorylation and nuclear translocation of active FoxO1, which causes cell cycle arrest and apoptosis (33). Finally, we examined whether RES induces apoptosis by inhibiting the PI3K/AKT signaling pathway. Cells were cultured by adding $\mathrm{H}_{2} \mathrm{O}_{2}$ or $\mathrm{H}_{2} \mathrm{O}_{2}+\mathrm{RES}$ for 3 days. After this treatment, apoptosis was determined. Treatment of RAW 264.7 cells with $10^{-5}$ M RES promoted apoptosis $(\mathrm{P}<0.01)$ (Fig. 8). Based on the data, it was revealed that RES induced apoptosis and as a result restrained osteoclastogenesis via suppressing the PI3K/AKT signaling pathway.

\section{Discussion}

RES, a natural polyphenolic component, is known to exert numerous beneficial pharmacological effects including antitumor, scavenging free radical and anti-inflammatory activities (22-24). Clinical and experimental investigations suggest that RES prevents bone loss by attenuating the damage of oxidative stress $(25,26)$. Furthermore, a previous study of our group demonstrated that OPG production was boosted, whereas RANKL synthesis was decreased in RES-treated OVX rats, and hence consequently osteoclast formation and differentiation were prevented (34). More importantly, RES had no toxic effect and therefore can be safely used even for the long-term treatment and/or prevention of osteoporosis (30). However, the underlying molecular mechanisms of how RES, a natural antioxidant, plays a major role in preventing bone loss, has not yet been fully elucidated. In the present study, we explored the potential molecular mechanisms of RES against osteoporosis. 


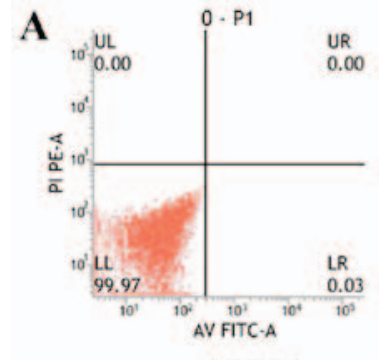

Control
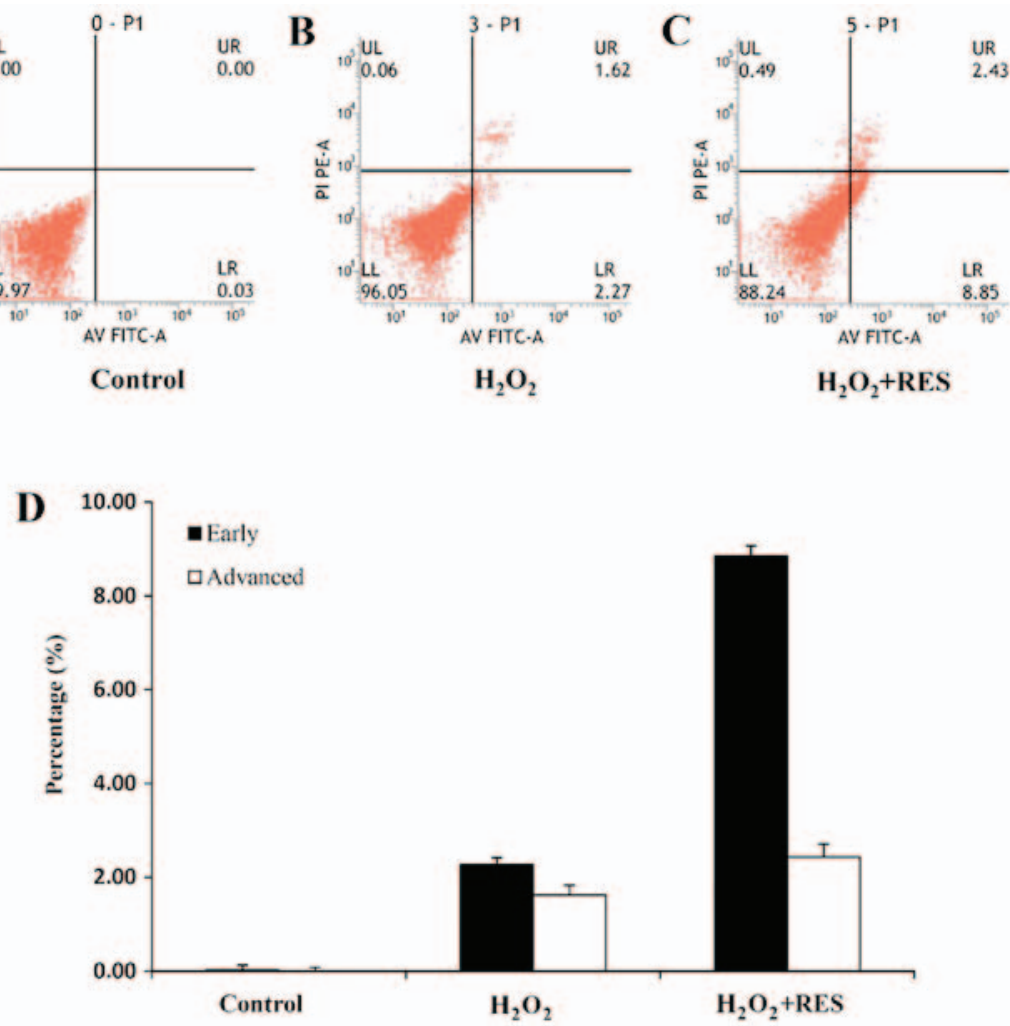

Figure 8. RAW 264.7 cell apoptosis is induced by resveratrol (RES). RAW 264.7 cells were incubated with $\mathrm{H}_{2} \mathrm{O}_{2}$ or $\mathrm{H}_{2} \mathrm{O}_{2}+\mathrm{RES}$ for 3 days. At the end of the incubation period, the cells were harvested, and apoptosis analysis was performed. Cell apoptosis (A-C) was statistically analyzed (D). P<0.05.

Our results demonstrated that, by improving the oxidative stress status, RES enhanced the ratio of OPG/RANKL (namely, OPG enhancement vs. RANKL decrease), suppressed osteoclastogenesis, and thus eventually attenuated bone resorption and prevented bone loss in vivo. Simultaneously, in vitro, the activity along with the function of osteoclasts was facilitated following exposure to $10^{-4} \mathrm{M} \mathrm{H}_{2} \mathrm{O}_{2}$, but these were inhibited in the presence of RES owing to its effect of relieving the oxidative stress damage. Apart from the above findings, RES was able to induce apoptosis of RAW 264.7 cells and thus restrained osteoclastogenesis. Moreover, at the molecular level, we confirmed that RES upregulated the transcriptional activity of FoxO1 by inhibiting the PI3K/AKT signaling pathway, and caused protection against oxidative damage and inhibited osteoclastogenesis in osteoporosis.

Oxygen-derived free radicals are produced as by-products of aerobic metabolism. This process occurs primarily in mitochondria due to electron escape passing through the electron transport chain $(35,36)$, and generates highly reactive and short-lived superoxide that is rapidly converted to the more stable and less reactive $\mathrm{H}_{2} \mathrm{O}_{2}$ (37-39). $\mathrm{H}_{2} \mathrm{O}_{2}$, as the most abundant form of ROS, diffuses freely through the mitochondrial membranes into the cytosol (37-39). Oxidative stress is the result of elevated ROS, which damages protein, lipids, and DNA and eventually triggers cell death. $\mathrm{H}_{2} \mathrm{O}_{2}$ additionally serves usually as both an extracellular and intercellular signal molecule (40). In the present study, $10^{-4} \mathrm{M} \mathrm{H}_{2} \mathrm{O}_{2}$ was used to induce oxidative stress.

RANKL and its receptor, pivotal factors required for osteoclast differentiation, are fundamental and necessary to promote osteoclastogenesis (41). RANKL plays a dominant role in activation of the osteoclast differentiation program, including the necessary genes required for bone resorption and for fusion of monocyte progenitor cells (42). When it binds to RANK, it triggers several intracellular signaling pathways in osteoclast precursor cells, ultimately inducing the expression of osteoclast-specific genes. OPG, as an inhibitor of RANKL, also binds to RANK to antagonize the effect of RANKL and thereby regulates osteoclast activity and function in the bone. We here employed the mouse macrophage cell line, namely, RAW 264.7 cells, and stimulated the cells with $100 \mathrm{ng} / \mathrm{ml}$ RANKL to induce osteoclastogenesis (32).

There have been several previous studies providing key evidence that ROS take part in bone regulation. ROS, especially $\mathrm{H}_{2} \mathrm{O}_{2}$, may be involved in the regulation of osteoclast formation (43), and has been observed both in vitro and in vivo to be produced by osteoclasts (44-46). On the other hand, $\mathrm{H}_{2} \mathrm{O}_{2}$ production in differentiated osteoclasts can also be stimulated by RANKL (47). Bartell et al found that RANKL promotes the accumulation of $\mathrm{H}_{2} \mathrm{O}_{2}$ in osteoclasts and in their progenitors. In turn, $\mathrm{H}_{2} \mathrm{O}_{2}$ improves osteoclast progenitor proliferation (11). Furthermore, Kim et al provided evidence that ROS play an important role in osteoclast differentiation through $\mathrm{NF}-\kappa \mathrm{B}$ regulation, while the antioxidant $\alpha$-lipoic acid inhibits osteoclast differentiation by reducing $\mathrm{NF}-\kappa \mathrm{B}$ DNA binding and has a potential therapeutic effect against bone erosive diseases (48). Additionally, ROS enhanced the expression of RANKL in mouse and human MG63 cells (9). Therefore, the increased ROS (particularly the $\mathrm{H}_{2} \mathrm{O}_{2}$ ) level is a critical regulatory-step of osteoclastogenesis and hence bone 
resorption, which is not a mere epiphenomenon of increased mitochondria number and/or function required to meet the high-energy demands of osteoclastic bone resorption (11).

Our findings showed that OVX induced oxidative stress (ROS and MDA increased, yet SOD and GSH-PX decreased in the OVX group, compared with the Sham group), and simultaneously promoted a decrease in the OPG level, an increase in the RANKL level, increased production of TRAP-5b and damaged bone microstructure. TRAP-5b in the serum, as a bone resorption marker enzyme, released by osteoclasts, well reflects the osteoclast activity directly along with bone resorption status in vivo. Meanwhile, in vitro, $10^{-4} \mathrm{M} \mathrm{H}_{2} \mathrm{O}_{2}$ used to induce oxidative stress resulted in the enhanced expression levels of osteoclast-specific enzymes (MMP-9, TRAP and cathepsin $\mathrm{K}$ ), indicating that osteoclast activity and function were elevated. In contrast, the treatment of the OVX rats with RES significantly reversed these changes in vivo. RES, conferring antioxidant power, effectively decreased RANKL together with the TRAP-5b level, but elevated the OPG level and attenuated bone microarchitecture damage. Notably, the results demonstrated that RES, due to its antioxidant effect, suppressed the RANKL production in the OVX rats. In other words, the increased ROS level promoted the production of RANKL and then stimulated osteoclast differentiation and bone resorption. This conclusion is consistent with previous studies $(9,11,47,48)$. Subsequently, the in vitro study demonstrated that RES at the concentration of $10^{-5} \mathrm{M}$ improved the oxidative stress status of cells and inhibited the expression of osteoclast-specific enzymes. These data indicate that RES has a significant bone protective effect via antagonizing oxidative stress to suppress osteoclast formation together with bone resorption activity both in vitro and in vivo. Therefore, the reduction of ROS production may be a rational approach for the treatment of diseases associated with high bone resorption, including, for example, osteoporosis and arthritis. FoxO1 activation in osteoclasts could be one valid approach to achieve this goal. Notably, an important finding of this study is that the redox regulator FoxO1 is a target of RES resisting oxidative stress and inhibiting osteoclastogenesis.

As important protein resistance to oxidative stress, FoxOs regulate the expression of antioxidant enzymes, where FoxO1 is a major member of the FoxO family. Through cell-specific deletion and molecular analyses, among the 4 FoxO proteins, FoxO1 is the only factor required for proliferation and redox balance in osteoblasts, and as a result FoxO1 controls bone formation (12). FoxO1 is regulated predominantly through the $\mathrm{PI} 3 \mathrm{~K} / \mathrm{AKT}$ signaling pathway and the FoxO1 protein is phosphorylated by the PI3K/AKT pathway, leading to inhibition of FoxO1-dependent transcription and impaired ability of DNA binding (49). AKT has been shown to directly phosphorylate and inactivate FoxO1, which results in cytoplasmic retention, inactivation and inhibition of the expression levels of FoxO1-regulated genes that control various processes such as metabolism, cell cycle, cell death and oxidative stress (50). In contrast, inhibition of the PI3K/AKT pathway induces dephosphorylation and nuclear translocation of active FoxO1, and then these processes enhance FoxO1 transcriptional activity, causing cell cycle arrest and apoptosis (33). In hematopoietic stem cells, FoxO1 has been demonstrated to reduce ROS by upregulating the expression of antioxidant enzymes including peroxiredoxins, GSH-PX and catalase $(19,20)$. After the deletion of FoxO1 in cells of the hematopoietic lineage, the number of osteoclast progenitors is increased in the bone marrow (51). Particularly, Bartell et al showed that RANKL promotes the accumulation of $\mathrm{H}_{2} \mathrm{O}_{2}$ in osteoclasts and their progenitors via an AKT-mediated repression of FoxO1 transcription that lowers catalase protein level. They also demonstrated that as a consequence of the loss of FoxO1 function, the osteoclast number and bone resorption are prevented by the systemic administration of catalase (11). This chain of events identify that FoxO1 is a major control node of osteoclastogenesis and bone resorption, both in physiologic or pathologic conditions. Furthermore, other studies elucidated that FoxO1 also plays a crucial role in bone metabolism by influencing osteoblast physiology and function, due to its ability to maintain redox balance via ROS-dependent or -independent mechanisms $(12,51,52)$.

In view of the facts that FoxO1 can maintain redox balance and play a central role in bone metabolism and FoxO1 protein can be phosphorylated by AKT, the inhibition of the PI3K/AKT pathway and regulation of FoxO1 transcriptional activity could be regarded as an effective and novel strategy for the prevention and/or treatment of osteoporosis. Moreover, our previous studies revealed that the effects of the FoxO1/ $\beta$-catenin signaling pathway on the proliferation and differentiation of osteoblasts is achieved through its regulation of the redox balance (upregulating antioxidant enzyme levels as well as the expression of DNA damage-repair-related gene Gadd45, while inhibiting the expression of apoptosis-related gene Bim along with the osteoblast inhibition gene PPAR- $\gamma$ ). In contrast, RES regulates the expression of FoxO1 by inhibiting the PI3K/AKT signaling pathway to control white adipose tissue and then to ameliorate overweight condition induced by a high fat diet. Based on the above studies, we speculated that RES regulates FoxO1 transcriptional activity by the PI3K/AKT signaling pathway to remedy oxidative damage in osteoporosis. In order to support this hypothesis, we explored the effect of RES on the PI3K/AKT pathway. In this study, we revealed that more osteoclasts were formed, and the osteoclast activity as well as function were much higher in the presence of $10^{-4} \mathrm{M} \mathrm{H}_{2} \mathrm{O}_{2}$ used to induce oxidative stress. This enhancement was confirmed by the higher mRNA levels of osteoclast-specific enzymes.

Moreover, the p-FoxO1 protein level and the ratio of $\mathrm{p}-\mathrm{AKT} / \mathrm{AKT}$ were increased in the osteoclasts in response to $\mathrm{H}_{2} \mathrm{O}_{2}$. The results indicated that $10^{-4} \mathrm{M} \mathrm{H}_{2} \mathrm{O}_{2}$ promoted osteoclast formation via the AKT-mediating inhibition of FoxO1 transcriptional activity. Taken together based on the findings in vivo, oxidative stress provokes RANKL production and RANKL promotes the accumulation of $\mathrm{H}_{2} \mathrm{O}_{2}$ in osteoclasts via AKT-mediated repression of FoxO1 transcription that lowers catalase protein level (11). Thus, we concluded that an antioxidant can upregulate the FoxO1 transcriptional activity by lowering the RANKL level. In addition, FoxO1 transcription activation can elevate the antioxidant enzyme levels, then lower $\mathrm{H}_{2} \mathrm{O}_{2}$ in osteoclasts, finally restraining osteoclastogenesis. This notion is consistent with previously studies showing that FoxO1 reduces ROS by boosting the antioxidant enzyme expression $(19,20)$. $N$-acetylcysteine, a radical scavenger, induces FoxO1 nuclear translocation and replenishes the FoxO1 level in homocysteine-treated osteoblasts (21). Here, the present study demonstrated that RES, 
a natural antioxidant, at a concentration of $10^{-5} \mathrm{M}$ enhancd the FoxO1 protein level together with transcriptional activity via suppressing AKT phosphorylation. In contrast, in the presence of RES, the antioxidant power of cells was enhanced, and RAW 264.7 cell apoptosis was also promoted. It was confirmed that RES enhanced the FoxO1 protein level and transcriptional activity to prevent oxidative damage, induction of apoptosis and inhibition of osteoclastogenesis. Accordingly, FoxO1 may be a novel and effective target of RES to play the role of resistance to osteoporosis.

RANKL binding to RANK on osteoclast precursors causes the recruitment of TNF receptor associated factor 6 (TRAF6). TRAF6 can activate several downstream signaling pathways, including NF- $\mathrm{B}$, c-Jun N-terminal protein kinase (JNK), extracellular signal-regulated kinase (ERK), p38, and PI3K/AKT (53-55). In particular, RANKL-induced activation of the PI3K/AKT signaling pathway has been shown to regulate osteoclast survival and differentiation (56). As mentioned above, RANKL-induced AKT activation downregulates FoxO1 transcription (11). Leonurine hydrochloride negatively regulates osteoclastogenesis by suppressing the $N F-\kappa B$ and PI3K/AKT signaling pathway. We here demonstrated that RES provoked FoxO1 dephosphorylation and upregulated FoxO1 transcriptional activity via suppressing the PI3K/AKT signaling pathway to achieve protection against oxidative damage, and inhibition of osteoclast activity, function, and formation. Moreover, our in vivo results demonstrated that RES inhibited RANKL production in OVX rats. Based on the above findings, we conclude that inhibition of the PI3K/AKT signaling pathway by RES was induced by RANKL, which requires further study to confirm.

In conclusion, the present study provides pivotal evidence that RES upregulates FoxO1 transcriptional activity by inhibiting the PI3K/AKT signaling pathway to obtain preventive effects against oxidative damage and inhibition of osteoclastogenesis. The study revealed the molecular mechanisms involved in the prevention of oxidative stress damage and inhibition of osteoclastogenesis by RES, and provides a new scientific basis for the clinical application of RES for the prevention and/or treatment of osteoporosis.

\section{Acknowledgements}

This study was supported by the National Natural Science Foundation of China under grant no. 81370970, and the Science and Technology Support Program of Gansu Province under grants no. 144FKCA075.

\section{References}

1. Ozgocmen S, Kaya H, Fadillioglu E and Yilmaz Z: Effects of calcitonin, risedronate, and raloxifene on ery throcyte antioxidant enzyme activity, lipid peroxidation, and nitric oxide in postmenopausal osteoporosis. Arch Med Res 38: 196-205, 2007.

2. Ershler WB, Harman SM and Keller ET: Immunologic aspects of osteoporosis. Dev Comp Immunol 21: 487-499, 1997.

3. Manolagas SC: From estrogen-centric to aging and oxidative stress: A revised perspective of the pathogenesis of osteoporosis. Endocr Rev 31: 266-300, 2010

4. Muthusami S, Ramachandran I, Muthusamy B, Vasudevan G, Prabhu V, Subramaniam V, Jagadeesan A and Narasimhan S: Ovariectomy induces oxidative stress and impairs bone antioxidant system in adult rats. Clin Chim Acta 360: 81-86, 2005.
5. Cervellati C, Bonaccorsi G, Cremonini E, Bergamini CM, Patella A, Castaldini C, Ferrazzini S, Capatti A, Picarelli V, Pansini FS, et al: Bone mass density selectively correlates with serum markers of oxidative damage in post-menopausal women. Clin Chem Lab Med 51: 333-338, 2013.

6. Baek KH, Oh KW, Lee WY, Lee SS, Kim MK, Kwon HS, Rhee EJ, Han JH, Song KH, Cha BY, et al: Association of oxidative stress with postmenopausal osteoporosis and the effects of hydrogen peroxide on osteoclast formation in human bone marrow cell cultures. Calcif Tissue Int 87: 226-235, 2010.

7. Yalin S, Bagis S, Polat G, Dogruer N, Cenk Aksit S, Hatungil R and Erdogan C: Is there a role of free oxygen radicals in primary male osteoporosis? Clin Exp Rheumatol 23: 689-692, 2005

8. Halliwell B: Free radicals, antioxidants, and human disease: Curiosity, cause, or consequence? Lancet 344: 721-724, 1994

9. Bai XC, Lu D, Liu AL, Zhang ZM, Li XM, Zou ZP, Zeng WS, Cheng BL and Luo SQ: Reactive oxygen species stimulates receptor activator of NF-kappaB ligand expression in osteoblast. J Biol Chem 280: 17497-17506, 2005.

10. Lee NK, Choi YG, Baik JY, Han SY, Jeong DW, Bae YS, Kim N and Lee SY: A crucial role for reactive oxygen species in RANKL-induced osteoclast differentiation. Blood 106: 852-859, 2005.

11. Bartell SM, Kim HN, Ambrogini E, Han L, Iyer S, Serra Ucer S, Rabinovitch P, Jilka RL, Weinstein RS, Zhao H, et al: FoxO proteins restrain osteoclastogenesis and bone resorption by attenuating $\mathrm{H}_{2} \mathrm{O}_{2}$ accumulation. Nat Commun 5: 3773, 2014.

12. Rached MT, Kode A, Xu L, Yoshikawa Y, Paik JH, Depinho RA and Kousteni S: FoxO1 is a positive regulator of bone formation by favoring protein synthesis and resistance to oxidative stress in osteoblasts. Cell Metab 11: 147-160, 2010.

13. Liu JW, Chandra D, Rudd MD, Butler AP, Pallotta V, Brown D, Coffer PJ and Tang DG: Induction of prosurvival molecules by apoptotic stimuli: Involvement of FOXO3a and ROS. Oncogene 24: 2020-2031, 2005.

14. Lehtinen MK, Yuan Z, Boag PR, Yang Y, Villén J, Becker EB, DiBacco S, de la Iglesia N, Gygi S, Blackwell TK, et al: A conserved MST-FOXO signaling pathway mediates oxidativestress responses and extends life span. Cell 125: 987-1001, 2006.

15. Nemoto S and Finkel T: Redox regulation of forkhead proteins through a p66shc-dependent signaling pathway. Science 295: 2450-2452, 2002.

16. Huang $\mathrm{H}$ and Tindall DJ: Dynamic FoxO transcription factors. J Cell Sci 120: 2479-2487, 2007.

17. Sengupta A, Molkentin JD, Paik JH, DePinho RA and Yutzey KE: FoxO transcription factors promote cardiomyocyte survival upon induction of oxidative stress. J Biol Chem 286: 7468-7478, 2011.

18. Subauste AR and Burant CF: Role of FoxO1 in FFA-induced oxidative stress in adipocytes. Am J Physiol Endocrinol Metab 293: E159-E164, 2007.

19. Tothova Z, Kollipara R, Huntly BJ, Lee BH, Castrillon DH, Cullen DE, McDowell EP, Lazo-Kallanian S, Williams IR, Sears C, et al: FoxOs are critical mediators of hematopoietic stem cell resistance to physiologic oxidative stress. Cell 128: 325-339, 2007.

20. de Keizer PL, Burgering BM and Dansen TB: Forkhead box o as a sensor, mediator, and regulator of redox signaling. Antioxid Redox Signal 14: 1093-1106, 2011.

21. Vijayan V, Khandelwal M, Manglani K, Singh RR, Gupta S and Surolia A: Homocysteine alters the osteoprotegerin/RANKL system in the osteoblast to promote bone loss: Pivotal role of the redox regulator forkhead O1. Free Radic Biol Med 61: 72-84, 2013.

22. Csiszar A: Anti-inflammatory effects of resveratrol: Possible role in prevention of age-related cardiovascular disease. Ann NY Acad Sci 1215: 117-122, 2011.

23. Baur JA, Pearson KJ, Price NL, Jamieson HA, Lerin C, Kalra A, Prabhu VV, Allard JS, Lopez-Lluch G, Lewis K, et al: Resveratrol improves health and survival of mice on a high-calorie diet. Nature 444: 337-342, 2006.

24. Pearson KJ, Baur JA, Lewis KN, Peshkin L, Price NL, Labinskyy N, Swindell WR, Kamara D, Minor RK, Perez E, et al: Resveratrol delays age-related deterioration and mimics transcriptional aspects of dietary restriction without extending life span. Cell Metab 8: 157-168, 2008.

25. Ungvari Z, Orosz Z, Rivera A, Labinskyy N, Xiangmin Z, Olson S, Podlutsky A and Csiszar A: Resveratrol increases vascular oxidative stress resistance. Am J Physiol Heart Circ Physiol 292: H2417-H2424, 2007. 
26. Ungvari Z, Bagi Z, Feher A, Recchia FA, Sonntag WE, Pearson K, de Cabo R and Csiszar A: Resveratrol confers endothelial protection via activation of the antioxidant transcription factor Nrf2. Am J Physiol Heart Circ Physiol 299: H18-H24, 2010.

27. Ungvari Z, Labinskyy N, Mukhopadhyay P, Pinto JT, Bagi Z, Ballabh P,Zhang C,Pacher P and Csiszar A: Resveratrol attenuates mitochondrial oxidative stress in coronary arterial endothelia cells. Am J Physiol Heart Circ Physiol 297: H1876-H1881, 2009.

28. Tamaki N, Cristina Orihuela-Campos R, Inagaki Y, Fukui M, Nagata T and Ito HO: Resveratrol improves oxidative stress and prevents the progression of periodontitis via the activation of the Sirt1/AMPK and the Nrf2/antioxidant defense pathways in a rat periodontitis model. Free Radic Biol Med 75: 222-229, 2014.

29. Bhattarai G, Poudel SB, Kook SH and Lee JC: Resveratrol prevents alveolar bone loss in an experimental rat model of periodontitis. Acta Biomater 29: 398-408, 2016.

30. Cottart $\mathrm{CH}$, Nivet-Antoine V, Laguillier-Morizot $\mathrm{C}$ and Beaudeux JL: Resveratrol bioavailability and toxicity in humans. Mol Nutr Food Res 54: 7-16, 2010.

31. Hsu H, Lacey DL, Dunstan CR, Solovyev I, Colombero A, Timms E, Tan HL, Elliott G, Kelley MJ, Sarosi I, et al: Tumor necrosis factor receptor family member RANK mediates osteoclast differentiation and activation induced by osteoprotegerin ligand. Proc Natl Acad Sci USA 96: 3540-3545, 1999.

32. Wei S, Teitelbaum SL, Wang MW and Ross FP: Receptor activator of nuclear factor-kappa b ligand activates nuclear factor-kappaB in osteoclast precursors. Endocrinology 142: 1290-1295, 2001.

33. Nakamura N, Ramaswamy S, Vazquez F, Signoretti S, Loda M and Sellers WR: Forkhead transcription factors are critical effectors of cell death and cell cycle arrest downstream of PTEN. Mol Cell Biol 20: 8969-8982, 2000.

34. Wang Y and Tang XL: Effects of resveratrol on osteoprotegerin and osteoprotegerin Ligand Expression of Femurs in Ovariectomized Rats. Chin J Clin Pharmacol Ther 13: 266-270, 2008.

35. Giorgio M, Trinei M, Migliaccio E and Pelicci PG: Hydrogen peroxide: A metabolic by-product or a common mediator of ageing signals? Nat Rev Mol Cell Biol 8: 722-728, 2007.

36. Newmeyer DD and Ferguson-Miller S: Mitochondria: Releasing power for life and unleashing the machineries of death. Cell 112: 481-490, 2003.

37. Balaban RS, Nemoto S and Finkel T: Mitochondria, oxidants, and aging. Cell 120: 483-495, 2005.

38. Chance B, Sies $\mathrm{H}$ and Boveris A: Hydroperoxide metabolism in mammalian organs. Physiol Rev 59: 527-605, 1979.

39. D'Autréaux B and Toledano MB: ROS as signalling molecules: Mechanisms that generate specificity in ROS homeostasis. Nat Rev Mol Cell Biol 8: 813-824, 2007.

40. Denisova NA, Cantuti-Castelvetri I, Hassan WN, Paulson KE and Joseph JA: Role of membrane lipids in regulation of vulnerability to oxidative stress in PC12 cells: Implication for aging. Free Radic Biol Med 30: 671-678, 2001.

41. Kong YY, Yoshida H, Sarosi I, Tan HL, Timms E, Capparelli C, Morony S, Oliveira-dos-Santos AJ, Van G, Itie A, et al: OPGL is a key regulator of osteoclastogenesis, lymphocyte development and lymph-node organogenesis. Nature 397: 315-323, 1999.

42. Levaot N, Ottolenghi A, Mann M, Guterman-Ram G, Kam Z and Geiger B: Osteoclast fusion is initiated by a small subset of RANKL-stimulated monocyte progenitors, which can fuse to RANKL-unstimulated progenitors. Bone 79: 21-28, 2015.
43. Suda N, Morita I, Kuroda T and Murota S: Participation of oxidative stress in the process of osteoclast differentiation. Biochim Biophys Acta 1157: 318-323, 1993.

44. Garrett IR, Boyce BF, Oreffo RO, Bonewald L, Poser J and Mundy GR: Oxygen-derived free radicals stimulate osteoclastic bone resorption in rodent bone in vitro and in vivo. J Clin Invest 85: 632-639, 1990.

45. Darden AG, Ries WL, Wolf WC, Rodriguiz RM and Key LL Jr: Osteoclastic superoxide production and bone resorption: Stimulation and inhibition by modulators of NADPH oxidase. J Bone Miner Res 11: 671-675, 1996.

46. Steinbeck MJ, Appel WH Jr, Verhoeven AJ and Karnovsky MJ: NADPH-oxidase expression and in situ production of superoxide by osteoclasts actively resorbing bone. J Cell Biol 126: 765-772, 1994.

47. Ha H, Kwak HB, Lee SW, Jin HM, Kim HM, Kim HH and Lee ZH: Reactive oxygen species mediate RANK signaling in osteoclasts. Exp Cell Res 301: 119-127, 2004.

48. Kim HJ, Chang EJ, Kim HM, Lee SB, Kim HD, Kim GS and Kim HH: Antioxidant- $\alpha$-lipoic acid inhibits osteoclast differentiation by reducing nuclear factor- $\kappa \mathrm{B}$ DNA binding and prevents in vivo bone resorption induced by receptor activator of nuclear factor- $\kappa \mathrm{B}$ ligand and tumor necrosis factor- $\alpha$. Free Radic Biol Med 40: 1483-1493, 2006

49. Van Der Heide LP, Hoekman MF and Smidt MP: The ins and outs of FoxO shuttling: Mechanisms of FoxO translocation and transcriptional regulation. Biochem J 380: 297-309, 2004.

50. Uddin S, Hussain AR, Siraj AK, Manogaran PS, Al-Jomah NA, Moorji A, Atizado V, Al-Dayel F, Belgaumi A, El-Solh H, et al: Role of phosphatidylinositol 3'-kinase/AKT pathway in diffuse large B-cell lymphoma survival. Blood 108: 4178-4186, 2006.

51. Ambrogini E, Almeida M, Martin-Millan M, Paik JH, Depinho RA, Han L, Goellner J, Weinstein RS, Jilka RL, O'Brien CA, et al: FoxO-mediated defense against oxidative stress in osteoblasts is indispensable for skeletal homeostasis in mice. Cell Metab 11: 136-146, 2010.

52. Iyer S, Ambrogini E, Bartell SM, Han L, Roberson PK, de Cabo R, Jilka RL, Weinstein RS, O'Brien CA, Manolagas SC, et al: FOXOs attenuate bone formation by suppressing Wnt signaling. J Clin Invest 123: 3409-3419, 2013.

53. Leibbrandt A and Penninger JM: RANK/RANKL: Regulators of immune responses and bone physiology. Ann NY Acad Sci 1143: $123-150,2008$

54. Asagiri $\mathrm{M}$ and Takayanagi $\mathrm{H}$ : The molecular understanding of osteoclast differentiation. Bone 40: 251-264, 2007.

55. Mandal CC, Ghosh Choudhury G and Ghosh-Choudhury N: Phosphatidylinositol 3 kinase/Akt signal relay cooperates with smad in bone morphogenetic protein-2-induced colony stimulating factor-1 (CSF-1) expression and osteoclast differentiation. Endocrinology 150: 4989-4998, 2009.

56. Moon JB, Kim JH, Kim K, Youn BU, Ko A, Lee SY and Kim N: Akt induces osteoclast differentiation through regulating the GSK3 $\beta /$ NFATc1 signaling cascade. J Immunol 188: 163-169, 2012.

(i) $\Theta$ This work is licensed under a Creative Commons Attribution-NonCommercial-NoDerivatives 4.0 International (CC BY-NC-ND 4.0) License. 